\title{
Preparation of Mesoporous Carbon with different Pore Wall structure via a temperature-programmed route for Lithium Sulfur Battery
}

\author{
Jing Wang, Yechun Lan, Lei Yan, Yufan Li, Zhiqiang Shi* \\ Tianjin Key Laboratory of Advanced Fibers and Energy Storage, College of Materials Science and \\ Engineering, Tianjin Polytechnic University, 399 Binshui West Road, Tianjin 300387, P. R. China \\ *E-mail: shizhiqiang@tjpu.edu.cn (Z.Shi).
}

doi: $10.20964 / 2018.08 .66$

Received: 7 April 2018 / Accepted: 4 June 2018 / Published: 5 July 2018

Due to the high specific surface area and large pore volume, mesoporous carbon materials are appealing for research interests to promote the performance of Lithium sulfur battery $(\mathrm{Li} / \mathrm{S})$. Herein, a mesoporous carbon (MC-1000) material, with high specific surface area $\left(1432 \mathrm{~m}^{2} \mathrm{~g}^{-1}\right)$ and large pore volume (2.894 $\mathrm{cm}^{3} \mathrm{~g}^{-1}$ ), is prepared via situ template method (using $\mathrm{MgO}$ as template), followed by pyrolysis at $1000{ }^{\circ} \mathrm{C}$ in nitrogen atmosphere. Temperature-programmed route is used to regulate the pore wall of MC-1000, and the modified MC-1000, MC-1300 and MC-1600 with similar specific surface area and pore volume are chosen for investigating the effect of micro-structure of MC on the performance of Li/S battery. HR-TEM images show graphited structure gradually formed with the regulated progress, and the increasing of pyrolyzation temperature may also improve the conductivity of $\mathrm{MC}$ and $\mathrm{MC} / \mathrm{S}$ composites. With an appropriate sulfur loading, MC-1300 and MC-1600 both present superior discharge capacity. Notably, MC-1300 and MC-1600 display high capacity of 1524 $\mathrm{mAh} \mathrm{g}^{-1}$ and $1415 \mathrm{mAh} \mathrm{g}^{-1}$, respectively, which is close to the theoretical specific capacity of sulfur.

Keywords: mesoporous carbon, pore wall, shuttle effect, lithium sulfur, large pore volume

\section{$\underline{\text { FULL TEXT }}$}

(C) 2018 The Authors. Published by ESG (www.electrochemsci.org). This article is an open access article distributed under the terms and conditions of the Creative Commons Attribution license (http://creativecommons.org/licenses/by/4.0/). 